\title{
Oxygen transfer study and modeling of plunging hollow jets
}

\author{
Munish Kumar $^{1}$ (1) $\cdot$ Subodh Ranjan ${ }^{1} \cdot$ N. K. Tiwari $^{1}$
}

Received: 9 May 2017 / Accepted: 4 June 2018 / Published online: 13 July 2018

(c) The Author(s) 2018

\begin{abstract}
Experiments were performed to study the effect of jet angle of hollow jet aerators on oxygen transfer of water. Three jet angles of $30^{\circ}, 45^{\circ}$ and $60^{\circ}$ were used to produce hollow jets impingement on the water in the pool. Results from experimental study showed a significant effect of hollow jet angle on volumetric oxygen transfer coefficient $\left(K_{L} a\right)$ at higher jet velocities. Standard oxygen transfer efficiency (SOTE) of $60^{\circ}$ hollow jet aerators is observed higher with low-kinetic-power jets, but at higher kinetic power, $30^{\circ}$ hollow jet aerator is observed to be the best in terms of SOTE. Moreover, modeling performance of the experimental data is evaluated by training and testing of the models, and empirical equations derived from multiple linear and multiple nonlinear regression techniques are compared with artificial neural network approach. The results of the present study are also compared with the previous studies of plunging jet aerators.
\end{abstract}

Keywords Hollow jet $\cdot$ Volumetric oxygen transfer coefficient $\cdot$ Standard oxygen transfer efficiency $\cdot$ Jet power $\cdot$ Artificial neural network

\section{Introduction}

Jet aeration occurs in many natural and practical situations involving pouring and filling of molten liquids, free fall of water from weir crest, breaking waves in sea and lakes, flowing water in rivers and canals, aerobic wastewater treatment and industrial processes, e.g., flotation of minerals, fermentation, cooling system in thermal industries, mixers in chemical industries (Sene 1988; Bin 1993; Deswal and Verma 2007a). Air is transferred and mixed to the submerged water region by plunging jets due to the exposure of surface area of jet to the ambient air of atmosphere before impingement into the water pool and a large turbulence is created. Air water biphasic region is produced in the form of air bubbles below the water surface by the insertion of high-velocity water jet. Plunging jet aerators achieve both aeration and mixing (Van de Sande and Smith 1975), and the contact area

Munish Kumar

munishmehta123@gmail.com

Subodh Ranjan

sranjan_nitk@yahoo.com

N. K. Tiwari

nand_nitk@rediffmail.com

1 Department of Civil Engineering, National Institute of Technology, Kurukshetra, Haryana, India between air and water below water surface determines the amount of oxygen transfer. High oxygen transfer is achieved with smaller bubbles having larger surface area than bubbles larger in size. The performance of a jet aerator is reflected by its efficiency to transfer oxygen into the aeration system. Volumetric oxygen transfer coefficient $K_{L} a$ and oxygen transfer efficiency are the two performance evaluation parameters influenced by various jet input parameters.

Studies conducted on jet aerators by varying parameters, viz. jet velocity, jet angle, length of jet, nozzle size and shape, indicated the effect of these parameters on oxygen transfer and entrainment of air. Investigations of Van de Sande (1974) on plunging jets having 10-mm-dia. nozzle suggested slightly decrease in oxygen transfer rate with diminishing angle. Ahmed (1974) and van de Donk (1981) researched over inclination angles of jet and found that oxygen transfer coefficient was weakly influence by angle of impact. Tojo et al. (1982) findings on inclination angle of two cylindrical nozzles ranged from $45^{\circ}$ to $90^{\circ}$ were significantly different from above studies and indicated that the jet impact angle of the nozzles considerably influences the oxygen transfer rate of a jet mixer, and the author suggested an optimum inclination angle of $60^{\circ}$ for efficient oxygen transfer and mixing. Ohkawa et al. (1986) experimented over inclined jets having angles of $45^{\circ}$ and $60^{\circ}$ and found no significant influence of inclination angle on oxygen transfer 
rate. Bagatur et al. (2002) investigated on the air entrainment characteristics of different shaped nozzles. Emiroglu and Baylar (2003) experimented on plunging venturi device having air holes on the convergent and divergent passage and observed the effect of location and number of air holes on air entrainment and oxygen transfer efficiency. Deswal and Verma (2007a) found the oxygen transfer efficiency of multiple jets higher up to 1.6 times than that of a single jet under similar conditions and correlated the oxygen transfer coefficient with jet parameters and no. of jets. Deswal and Verma (2007b) studied the performance of conical plunging jet aerator having jet angle of $60^{\circ}$ with smaller jet thicknesses and tested the validity of support vector machines modeling technique. Deswal (2011) used SVM and GP regression techniques in modeling oxygen transfer by multiple plunging jets. Singh et al. (2011) carried out the study to examine the oxygenation potential of various shapes of nozzle jets and suggested some relationships of oxygen transfer coefficient and penetration depths in terms of jet kinetic power for the used nozzle geometries. Deswal and Pal (2015) compared the performance of poly and RBF kernel function-based SVM in modeling mass transfer by vertical and inclined plunging jets. Chipongo and Khiadani (2016) studied oxygen transfer by multiple vertical plunging jets in tandem and observed the impact of various jet parameters on oxygen transfer. Jahromi and Khiadani (2017) have investigated the performance of nozzle jet discharging into turbulent cross-flow in a rectangular flume with varying jet impact angles, jet fall height, jet to cross-flow velocity ratio and depth of flow; and found substantially higher efficiency of nozzle jets in a cross-flow than the jets plunging into stagnant pool of water.

To sum up, there is a lot of work available in the literature that deals with the gas entrainment of plunging nozzle jets with varying jet parameters and jet geometries. Despite the encouraging performance of hollow jet aerators over some conventional aerators (Deswal and Verma 2007b), a few studies are available on hollow jet aeration devices. The current study investigates the oxygenation performance of hollow jet aerators of different jet inclination angles, and modeling techniques (multiple linear regression, multiple nonlinear regression, and artificial neural network) are employed to predict volumetric oxygen transfer coefficient of hollow jets. In addition to this, a comparison of current work is made with existing studies available in the literature.

\section{Oxygen transfer parameters}

The volumetric oxygen transfer coefficient $\left(K_{L} a\right)_{T}$ is the slope of semilogarithmic plot of the DO deficit against time (Ashley et al. 2013; Chipongo and Khiadani 2016), so the volumetric oxygen transfer coefficient at temperature of water at $T\left({ }^{\circ} \mathrm{C}\right)$ can be calculated as
$\left(K_{L} a\right)_{T}=\frac{1}{t} \operatorname{Ln}\left[\frac{C_{\mathrm{s}}-C_{0}}{C_{\mathrm{s}}-C_{t}}\right]$

where $\left(K_{L} a\right)_{T}=$ volumetric oxygen transfer coefficient $\left(\mathrm{s}^{-1}\right)$ at temperature $T\left({ }^{\circ} \mathrm{C}\right), C_{\mathrm{s}}=$ saturation concentration of oxygen in water $(\mathrm{mg} / \mathrm{L}), C_{0}=$ concentration of oxygen in water at time $t=0(\mathrm{mg} / \mathrm{L})$, and $C_{t}=$ concentration of oxygen in water at time $t$ in seconds $(\mathrm{mg} / \mathrm{L})$.

To provide a uniform basis of comparison of different systems, $K_{L} a$ is evaluated at standard conditions (Conway and Kumke 1966; Pillai et al. 1971; Daniil and Gulliver 1988). At standard conditions (clean water at $20^{\circ} \mathrm{C}$ temperature and 1 atmosphere pressure), volumetric oxygen transfer coefficient can be evaluated as

$K_{L} a=\left(K_{L} a\right)_{T}(1.024)^{(20-T)}$

where $K_{L} a=$ volumetric oxygen transfer coefficient $\left(\mathrm{s}^{-1}\right)$ at temperature $20^{\circ} \mathrm{C}$ and pressure of 1 atmosphere and $T=$ Test temperature of water $\left({ }^{\circ} \mathrm{C}\right)$.

The standard oxygen transfer rate $(\mathrm{kg} / \mathrm{h})$ can be calculated (Deswal and Verma 2007a) as

SOTR $=3.6 K_{L} a C_{S}^{*} V$

where SOTR is standard oxygen transfer rate $(\mathrm{kg} / \mathrm{h}), C_{\mathrm{S}}^{*}$ is saturation concentration of dissolved oxygen at standard conditions $(\mathrm{mg} / \mathrm{L})$, and $V$ is the volume of tank water $\left(\mathrm{m}^{3}\right)$.

The performance of a jet aeration system can be evaluated on the basis of standard oxygen transfer efficiency (Chipongo and Khiadani 2016) as

SOTE $=\frac{\text { SOTR }}{P}$

where SOTE is standard oxygen transfer efficiency $(\mathrm{kg} /$ $\mathrm{kW} \mathrm{h})$ and $P$ is jet kinetic power $(\mathrm{kW})$ estimated (Deswal and Verma 2007a) as

$P=0.0005 \rho Q V_{j}^{2}$

where $\rho$ is density of water $\left(\mathrm{kg} / \mathrm{m}^{3}\right), Q$ is jet flow rate $\left(\mathrm{m}^{3} / \mathrm{s}\right)$, and $V_{\mathrm{j}}$ is jet velocity $(\mathrm{m} / \mathrm{s})$

\section{Materials and methods}

\section{Hollow jet aeration device}

Plunging hollow jet aerator consists of a conical-shaped surface device that spreads water emerging out from the outlet of a discharging pipe into the atmosphere, thus forming a hollow jet issued at the exit end of pipe. The jet takes the form of somewhat circular water sheet advancing in all 
directions after emerging out through adjustable opening in between the exit end of the pipe and the conical surface of the aerator device. The jet goes on diverging as it advances and impinges on the water in the pool gradually sucking some of the air present in the space within the hollow jet and thus creates a large turbulence in the water in the pool. The aerator is installed at the pipe outlet with a centering and fixing arrangement such that the aerator remains co-axial with the pipe. The annular opening between the exit end of pipe and the aerator, making the aerator move upward and downward, can be adjusted by upward/downward movement of the aerator.

The cones fabricated of acrylic material are mounted on a bolt of $5 \mathrm{~mm}$ diameter which is connected by a bolt holder (14 mm diameter) using internal threads $(5 \mathrm{~mm})$ (Fig. 1). The position of the bolt holder was about $7 \mathrm{~cm}$ above the pipe exit. To make the bolt holder at the center of the pipe, 3 pairs of centering and fixing screws (side screws having $3 \mathrm{~mm}$ diameter) are tightened to the bolt holder as shown in Fig. 5. The centering and fixing screws are fixed to the pipe wall after tightening the bolt holder at the center. The wall thickness at the exit end of pipe was tapered to have the angle same as that of the jet angle of cone to ensure uniform jet at the outset. The centering of the bolt and the cone was ensured by the proper closing and tightening of the cone with the exit end of the pipe. The vertical distance $(Y)$ between the pipe exit and conical surface was measured by counting the number of threads on the bolt by which the cone moves downwards from the fully tightened position with the pipe exit. The calibration of the length of bolt threads was done by using a scale having measurement accuracy of $\pm 0.5 \mathrm{~mm}$. The rotation of the cone enables its vertical movement as well as the adjustment of annular space between conical surface and pipe exit. The annular gap between the conical surface of the aerator and the pipe wall is the thickness of jet, $T_{\mathrm{j}}$, calculated as $Y \cdot \cos \theta$, in which $Y$ is the axial vertical opening and $\theta$ is the jet angle in ${ }^{\circ}$, representing the inclination of jet with the surface of water in the pool. Three cones with $30^{\circ}, 45^{\circ}$ and $60^{\circ}$ inclination angles having exit end diameter of $65 \mathrm{~mm}$ (base diameter) were operated along with three pipe assemblies having exit wall angles identical to the cone angles.

The jet velocity $V_{\mathrm{j}}$ coming out from discharging pipe outlet having opening area of $\pi \cdot D \cdot Y \cdot \cos \theta$ can be calculated by dividing the discharge, $Q$, by the opening area of flow at the device exit. The jet impact velocity changed with the distance from the exit end of the aerator; therefore, in order to maintain jet impact characteristics similar during each experiment and to avoid the effect of distance, the device is kept almost touching the water surface in the tank at a constant jet length of $0.1 \mathrm{~m}$. This constant jet length is used with each inclination angle jets so that the comparative analysis of the jet angles would be uniform.

In this study, experiments were conducted on plunging hollow jet aerators of three jet angles of $30^{\circ}, 45^{\circ}$ and $60^{\circ}$ having jet thicknesses ranging from 4 to $17.3 \mathrm{~mm}$, installed at the exit end of a 50-mm-diameter (internal) pipe with the provision for adjustment of thickness of the jet produced.
Fig. 1 Hollow jet aeration device

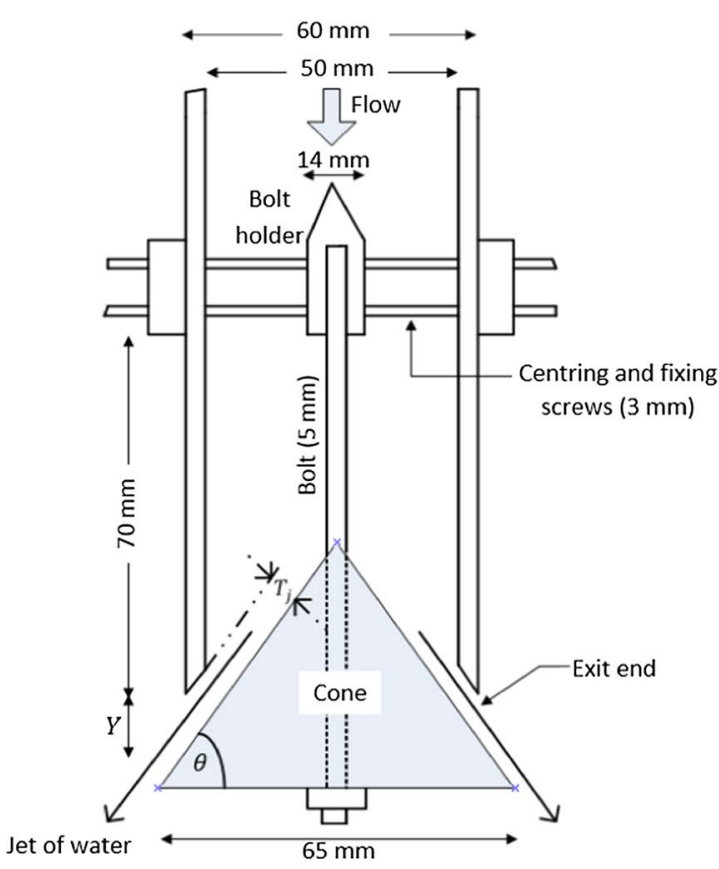

(a)

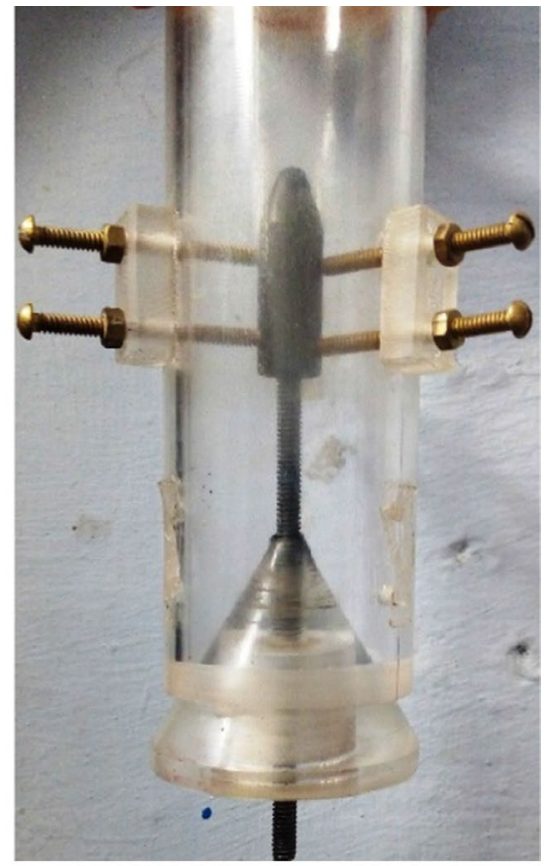

(b) 


\section{Determination of dissolved oxygen (DO)}

Azide modification method based on the guidelines provided in APHA et al. (2005) is employed to measure the quantity of oxygen dissolved in the tank water. The reagents are prepared as per the directions given in APHA et al. (2005). Three representative samples of testing water are collected in 300-mL BOD bottles: two samples containing the aerated water after running the aerator for $1 \mathrm{~min}$, and other sample containing the testing water prior to each test run. The measurement procedure is started by adding $1 \mathrm{~mL}$ of $\mathrm{MnSO}_{4}$ followed by $1 \mathrm{~mL}$ alkali-iodide-azide by using a pipette holding just above the sample surfaces. All the samples are thoroughly mixed after closing the lid of the bottles, and the precipitates are allowed to settle half the bottle volume. $\mathrm{H}_{2} \mathrm{SO}_{4}$ is then added to each of the samples and mixed until proper dissolution. After this, $200 \mathrm{~mL}$ sample of the original samples is titrated in a conical flask using a burette of least count of $\pm 0.1 \mathrm{~mL}$ containing sodium thiosulfate solution $\left(\mathrm{Na}_{2} \mathrm{~S}_{2} \mathrm{O}_{3}\right)$ after adding few drops of starch indicator to the testing samples. The volume of the $\mathrm{Na}_{2} \mathrm{~S}_{2} \mathrm{O}_{3}$ solution utilized in titration is noted in order to determine the initial and final DO of the representative samples.

\section{Experimental setup and methodology}

The schematic representation of the experimental setup is shown in Fig. 2.

The experimental setup involves an aeration tank having dimensions $1 \mathrm{~m} \times 1 \mathrm{~m} \times 1 \mathrm{~m}$ with a water circulating arrangement through a pipe of diameter $50 \mathrm{~mm}$ connected to a centrifugal pump, a flow regulating valve to control the rate of flow, a calibrated orifice meter to measure discharge of water flowing through pipe, and a thermometer to measure the temperature of water in the tank. Tap water was used for all the experiments, and the level of water in aeration tank was maintained constant nearly at $0.65 \mathrm{~m}$. Hollow jet aerating device connected to the outlet of vertical pipe was installed at a height of $0.1 \mathrm{~m}$ from the water surface throughout the experimentation. The experiments were conducted with jet velocities ranging from 0.7 to $4.77 \mathrm{~m} / \mathrm{s}$ under a discharge range of 2.3 to $3.6 \mathrm{~L} / \mathrm{s}$. Thickness of jet was manually adjusted by scaling the vertical opening between pipe outlet and aerator end. For obtaining the amount of oxygen transferred to water in the tank for a particular jet aerator, a known volume of water was filled in the tank. An estimated quantity of sodium sulfite $\left(\mathrm{Na}_{2} \mathrm{SO}_{3}\right)$ along with cobalt chloride $\left(\mathrm{CoCl}_{2}\right)$ as catalyst was added to bring dissolved oxygen level of water in the tank between 1.0 and $2.0 \mathrm{mg} / \mathrm{L}$ (Deswal 2008), and a sample of water was taken for initial $\mathrm{DO}\left(C_{0}\right)$ measurement. Then, the aerator was allowed to run for a specified period of time. (It was ensured that the device was run for a period $(t)$ that DO of water in the tank does not reach the saturation value at the test temperature, $T^{\circ} \mathrm{C}$, and the final DO $\left(C_{t}\right)$ was then measured.) Two samples are collected from the tank for final DO determination, and the average DO value of two samples is considered as final DO $\left(C_{t}\right)$. The temperature of water in the tank is measured by a mercury thermometer with a minimum accuracy of $\pm 0.1^{\circ} \mathrm{C}$. The procedure was repeated for various runs of observations by using different jet aerators. The value of volumetric oxygen transfer coefficient $\left(K_{L} a\right)$ was then estimated.

\section{Experimental results}

Angle of jet plays an effective role in influencing the oxygen transfer of plunging jets (Tojo et al. 1982; Deswal 2008; Jahromi and Khiadani 2017). These researchers recommended jet angle of $60^{\circ}$ for significant oxygen transfer in the water pool by the cylindrical impinging jets. In the present study,

Fig. 2 Experimental setup

Differential Mercury Manometer

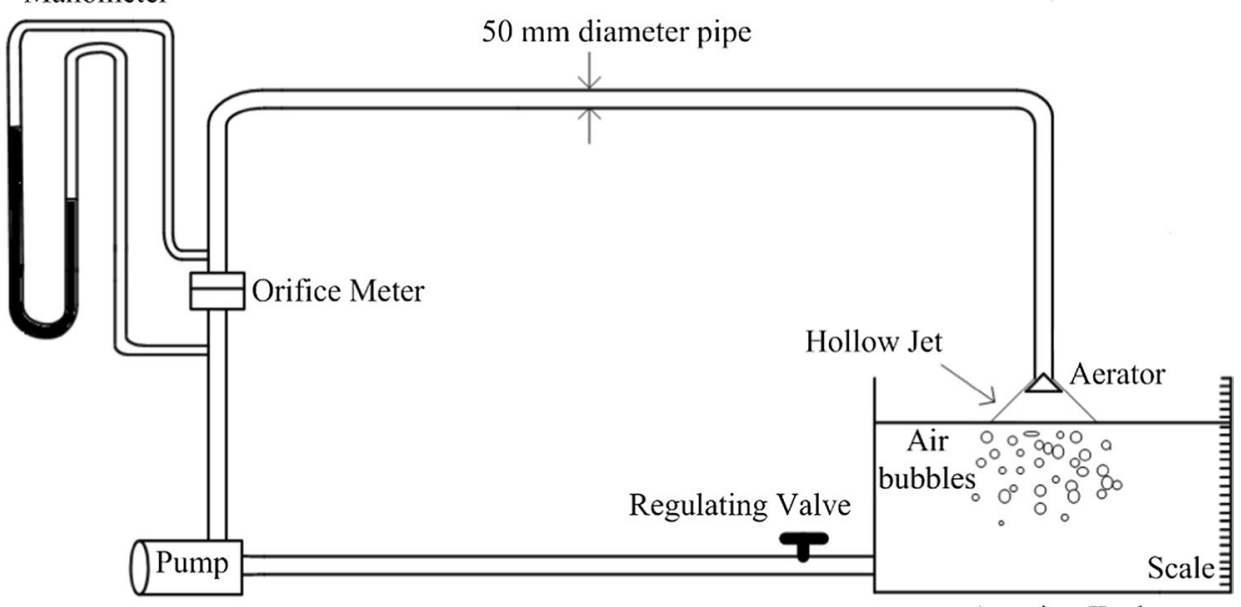

Aeration Tank
لودينة الملك عبدالعزيز

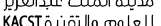


the influence of jet angle becomes prominent at higher jet velocities $\left(V_{\mathrm{j}}{ }^{2} 2 \mathrm{~m} / \mathrm{s}\right)$ in case of hollow jets. As illustrated in Fig. 3, the impact of jet angle is not significant at smaller velocities; the oxygen transfer is observed getting effected with jet angle at higher jet velocities only. A noticeable increase in $K_{L} a$ is observed as the jet velocity increases for all the jet angles tested as reported in the previous studies. The increased kinetic energy and jet momentum of highvelocity jets create intense turbulence and high shear in the water and increase the oxygenation of pool water. The characteristics of hollow jets are much different to the nozzle jets as the aeration device exposes much larger surface area of jet into the atmosphere by creating a circular water sheet, and the impingement develops a hollow spaced conical jet within the pool of water rather than impinging in the form of a solid jet. The impact of jet velocity on the $K_{L} a$ with variation of jet angles is depicted in Fig. 3. The deviation of flow is larger in hollow jet angle of $30^{\circ}$, creating large disturbances and much higher turbulence to the pool water surface at higher velocity, encompassing more air above the water surface rather than impacting deep into the water pool, and rapidly generating air-water interfaces by producing a much larger contact area. Although the oxygenation performance is encouraging with hollow jet angle of $30^{\circ}$ compared to the other angles, still, the angle is envisaged to be not so effective with deep aeration pools, the reason being that the larger expansion of jet results in shallow penetration into the pool and reduces the jet activity at the lower section of the tank. This angle cannot be investigated further for higher velocity ranges beyond $3.7 \mathrm{~m} / \mathrm{s}$ due to tank area limitations because the jet flow was effected by walls of the aeration tank. From Fig. 3, analyzing best fit curve of $K_{L} a$ values for the jet angles, it is inferred that $K_{L} a$ curve achieved with hollow jet inclination angle of $60^{\circ}$ is higher than the jet angle of $45^{\circ}$ beyond the jet velocity of $2 \mathrm{~m} / \mathrm{s}$, and the impact becomes stronger with the increase in jet velocity. The addition of oxygen by the jet impact angle of $45^{\circ}$ is lower than the jet angle of $60^{\circ}$ possibly due to increased bubble interaction time with the pool water resulting from deeper jet penetration with higher jet angle, and thus, the surface activity caused by larger deviation angle $\left(45^{\circ}\right)$ is overcome by deep interaction of jet with hollow angle of $60^{\circ}$ resulting in higher oxygen transfer.

The impact of jet kinetic power $(P / V)$ on $K_{L} a$ and SOTE for hollow jet inclination angles of $60^{\circ}, 45^{\circ}$ and $30^{\circ}$ is presented on the plots illustrated by Figs. 4, 5 and 6, respectively. $K_{L} a$ consistently increases with the increase in jet power, while SOTE values gradually decrease with the increase in kinetic jet power, similar to the findings of previous researchers. Low-power jets had higher oxygen transfer efficiency values, and SOTE starts declining as $P / V$ increases for whole range of experiments with all the three jet angles tested. From Fig. 7, analyzing the best fit lines of the three angles tested, SOTE curve of jet angle $45^{\circ}$ is observed lowest for the whole range of kinetic jet power tested which is ascribed to the lower values of $K_{L} a$ relative to other jet angles for the all velocity ranges. Figure 7 shows that at low kinetic power $\left(P / V^{<} 0.004 \mathrm{~kW} / \mathrm{m}^{3}\right)$ SOTE value of $30^{\circ}$ aerator is slightly lower than $60^{\circ}$ aerator, but improves significantly with the increase in kinetic jet power and the highest efficiencies are observed with $30^{\circ}$ hollow jet aerator at higher $P / V$ values $\left(P / V^{>} 0.005 \mathrm{~kW} / \mathrm{m}^{3}\right)$. The SOTE values of $30^{\circ}$ and $60^{\circ}$ hollow jets are observed noticeably higher than $45^{\circ}$ hollow jets for the entire range of experiments (Fig. 7). The surface of pool water is vigorously agitated with the formation of eddies and sideways movement of water jet below and close to the water surface increases the interfacial area of pool water, and this progresses further with the increase in jet velocities. On average basis, the overall increment in SOTE for the jet angle of $30^{\circ}$ relative to jet angle of $60^{\circ}$ and
Fig. 3 Variation of volumetric oxygen transfer coefficient with jet velocity indicating the effect of jet angle (in ${ }^{\circ}$ )

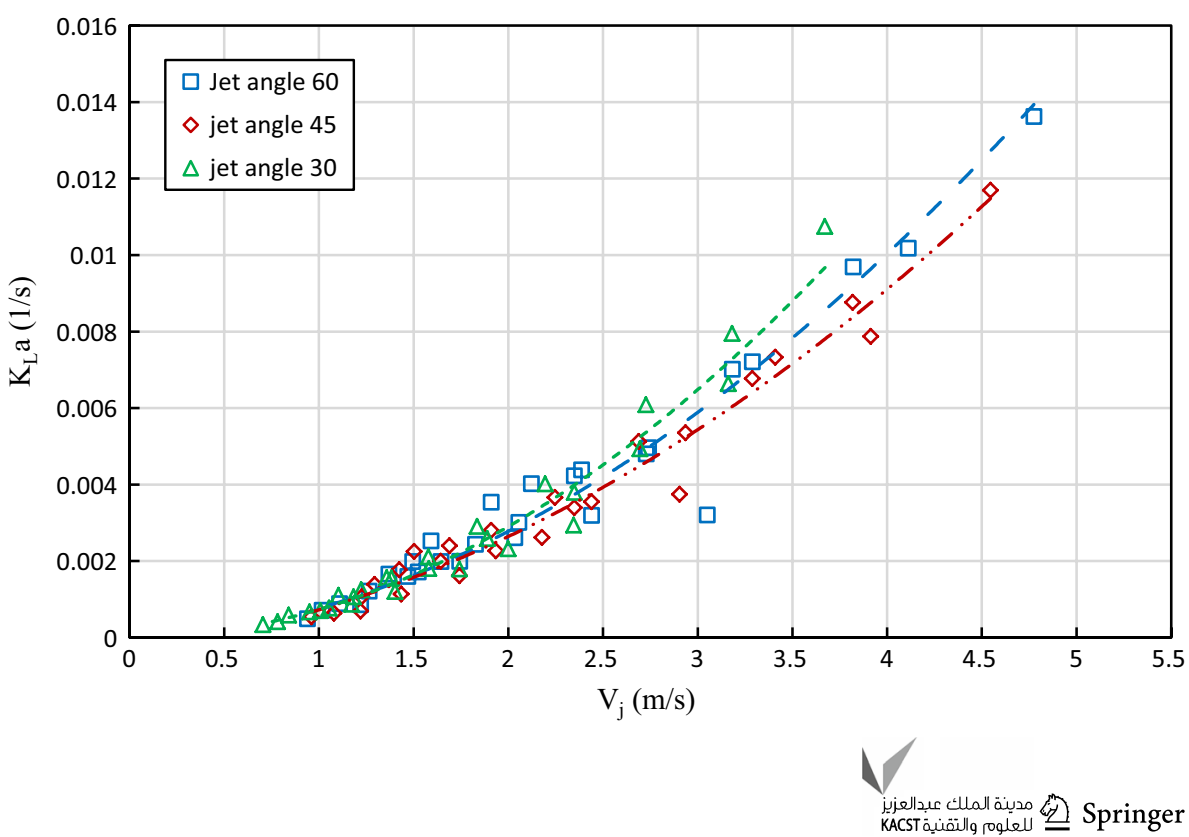


Fig. $4 K_{L} a$ and SOTE as a function of kinetic jet power per unit volume $(P / V)$ of water $\left(\theta=60^{\circ}\right)$

Fig. $5 K_{L} a$ and SOTE as a function of kinetic jet power per unit volume $(P / V)$ of water $\left(\theta=45^{\circ}\right)$

Fig. $6 K_{L} a$ and SOTE as a function of kinetic jet power per unit volume $(P / V)$ of water $\left(\theta=30^{\circ}\right)$
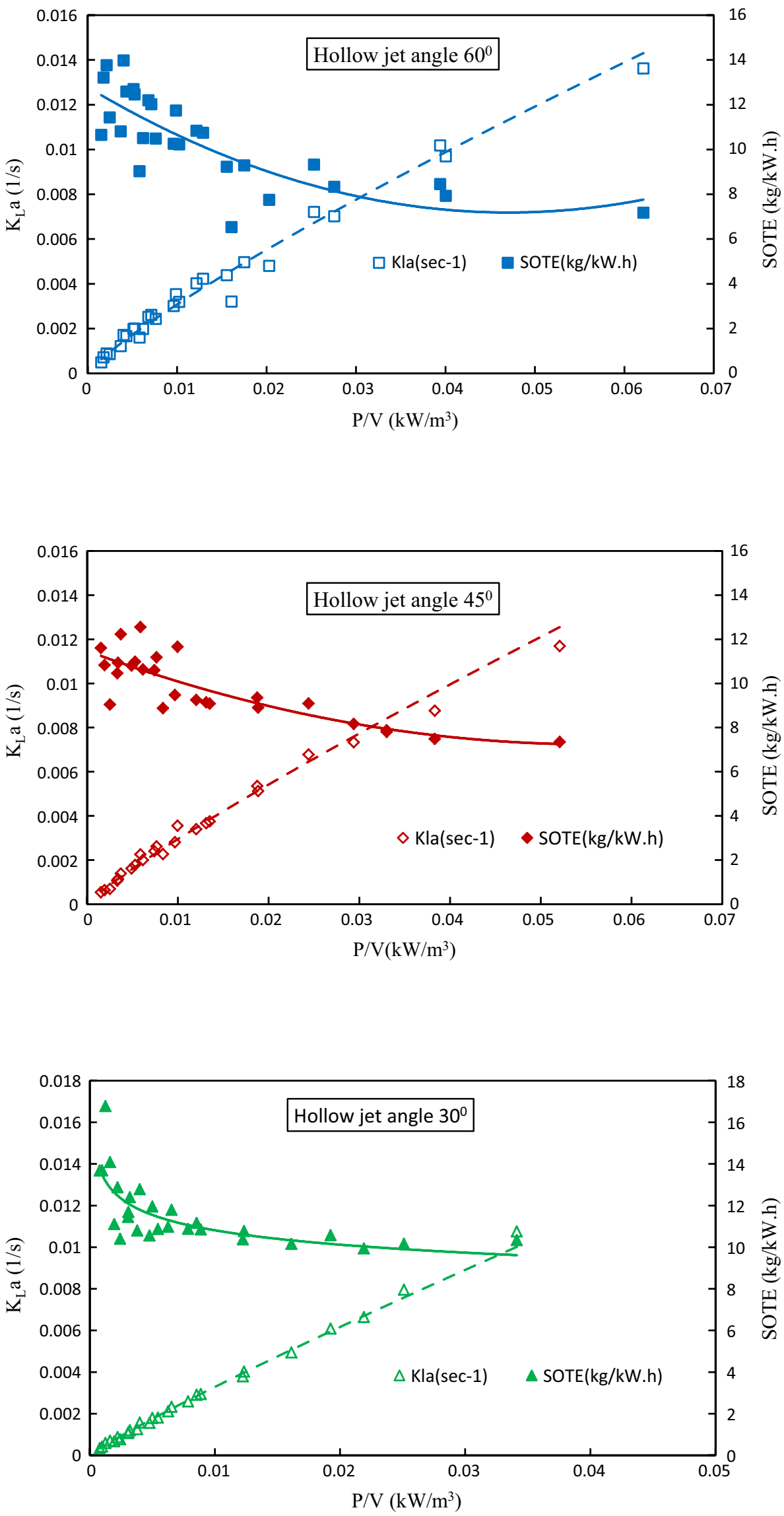
Fig. 7 Variation of SOTE with jet power per unit volume $(P / V)$ indicating the effect of jet angle $\left(\right.$ in $\left.^{\circ}\right)$

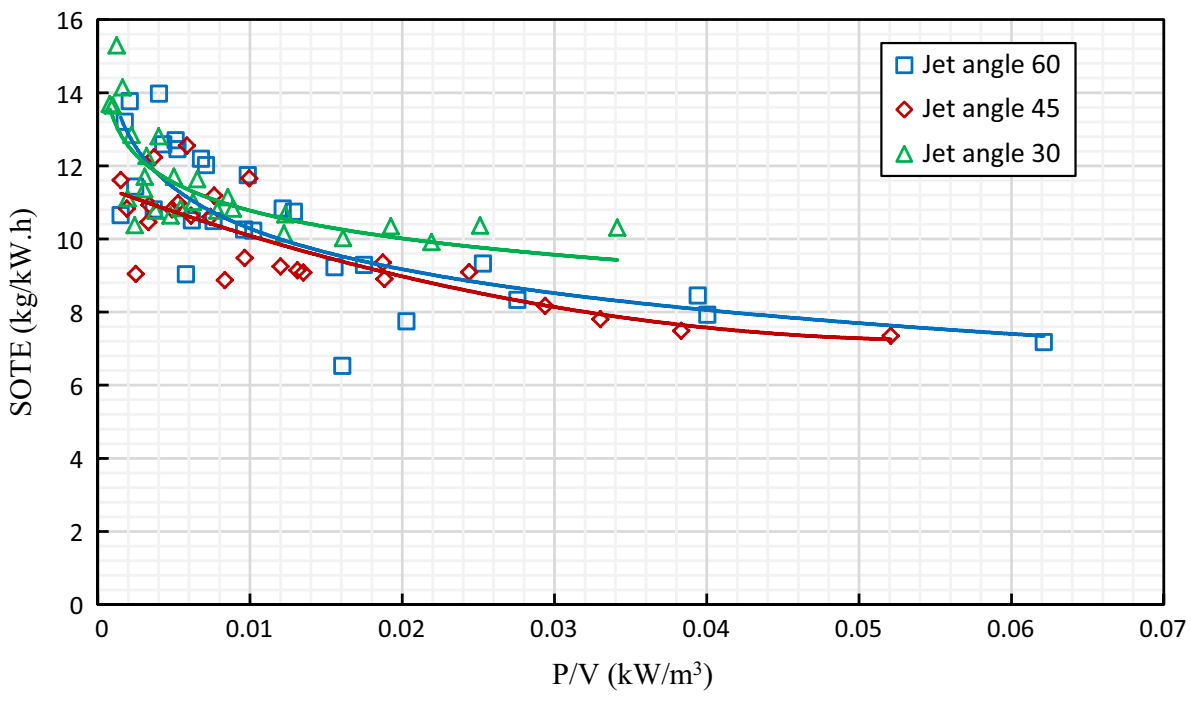

$45^{\circ}$ is observed as 10.5 and $17.3 \%$, respectively, while the overall gain in SOTE by $60^{\circ}$ jet angle over $45^{\circ}$ is observed as $6.1 \%$. The SOTE in this study is observed higher than in the study conducted by Deswal and Verma (2007b) on conical plunging jet aerator (Table 6) probably because higher thickness range tested in current study leads to more surface instabilities and deeper jet submergence due to high shear and momentum with thicker jets. Table 1 summarizes the results of volumetric oxygen transfer coefficient $\left(K_{L} a\right)$ and standard oxygen transfer efficiency (SOTE) for the jet angles utilized in this study.

\section{Modeling}

The soft computing-based modeling techniques are very popular in the field of water resources and environmental engineering. A lot of studies in the literature discuss the use of modeling techniques, viz. support vector machines (SVM), artificial neural network (ANN), multivariate regression function-based relationships (MLR and MNLR), gene expression programming (GEP), Gaussian process regression (GP) (Onen 2014; Sihag et al. 2017, 2018a, b, c; Singh et al. 2017; Kumar et al. 2018). In this study, relationships based on multiple linear and nonlinear regression are compared with the back propagation artificial neural network technique.

\section{Data set}

The modeling study is based on the current experimental data obtained from oxygenation study of plunging hollow jet aerators. Jet parameters, viz. jet thickness $\left(T_{\mathrm{j}}\right)$, jet velocity $\left(V_{\mathrm{j}}\right)$ and jet angle $(\sin \theta)$, are considered as inputs, and volumetric oxygen transfer coefficient $\left(K_{L} a\right)$ is considered as output for model building and validation. The complete data set is divided into training and testing data sets. Out of 80 experimental observations, 56 observations (70\%) are selected for training the models and 24 observations (30\%), randomly selected from the complete data set, are utilized for validation of the models. The details of the data set are provided in Table 2.

\section{Artificial neural network}

Neural networks are general-purpose computing tools that can solve complex nonlinear problems (Fischer 1998). The network comprises a large number of simple processing elements linked to each other by weighted connections according to a specified architecture. These networks learn from the training data by adjusting the connection weights (Bishop, 1995). Every neuron in the network computes a weighted by $W_{i j}$ sum of its $p$ input $x_{i}$, for $i=0,1,2 \ldots \mathrm{n}$ hidden layer and then applies a nonlinear activation function to produce an output $u_{j}$. The formation of this function is:

$u_{j}=\sum_{i=0}^{n} W_{i j} x_{i}$

In this study, multilayer perceptron neural network (MLP) with back propagation algorithm consisting of three layers: first, an input layer, representing input variables $(i)$, second, a hidden layer $(j)$ and third, an output layer $(k)$, is used. Each layer is interconnected by weights $W_{i j}$ and $W_{j k}$, every unit sums its inputs and adds a bias or threshold term to the sum, and this sum is then transformed by an activation function to produce an output (Quej et al. 2017). Logistic sigmoid function (Eq. 8) is used as an activation function in this study.

$f\left(u_{j}\right)=\frac{1}{1+e^{-u_{j}}}$ 
Table 1 Results of $K_{L} a$ and SOTE for the jet angles

\begin{tabular}{|c|c|c|c|c|c|c|}
\hline Sr. no & Jet angle $(\theta)$ & $Y(\mathrm{~mm})$ & $T_{\mathrm{j}}(\mathrm{m})$ & $V_{\mathrm{j}}(\mathrm{m} / \mathrm{s})$ & $K_{L} a\left(\mathrm{~s}^{-1}\right)$ & $\begin{array}{l}\text { SOTE } \\
(\mathrm{kg} / \\
\mathrm{kW} \mathrm{h})\end{array}$ \\
\hline 1 & $60^{\circ}$ & 8 & 0.004 & 4.8 & 0.01362 & 7.2 \\
\hline 2 & $60^{\circ}$ & 10 & 0.005 & 3.8 & 0.00969 & 7.9 \\
\hline 3 & $60^{\circ}$ & 12 & 0.006 & 3.2 & 0.00702 & 8.3 \\
\hline 4 & $60^{\circ}$ & 14 & 0.007 & 2.7 & 0.00480 & 7.7 \\
\hline 5 & $60^{\circ}$ & 16 & 0.008 & 2.4 & 0.00438 & 9.2 \\
\hline 6 & $60^{\circ}$ & 18 & 0.009 & 2.1 & 0.00402 & 10.8 \\
\hline 7 & $60^{\circ}$ & 20 & 0.01 & 1.9 & 0.00354 & 11.7 \\
\hline 8 & $60^{\circ}$ & 24 & 0.012 & 1.6 & 0.00253 & 12.2 \\
\hline 9 & $60^{\circ}$ & 26 & 0.013 & 1.5 & 0.00160 & 9.0 \\
\hline 10 & $60^{\circ}$ & 8 & 0.004 & 4.1 & 0.01018 & 8.5 \\
\hline 11 & $60^{\circ}$ & 10 & 0.005 & 3.3 & 0.00721 & 9.3 \\
\hline 12 & $60^{\circ}$ & 12 & 0.006 & 2.7 & 0.00497 & 9.3 \\
\hline 13 & $60^{\circ}$ & 14 & 0.007 & 2.3 & 0.00423 & 10.7 \\
\hline 14 & $60^{\circ}$ & 16 & 0.008 & 2.1 & 0.00301 & 10.3 \\
\hline 15 & $60^{\circ}$ & 18 & 0.009 & 1.8 & 0.00244 & 10.5 \\
\hline 16 & $60^{\circ}$ & 20 & 0.01 & 1.6 & 0.00199 & 10.5 \\
\hline 17 & $60^{\circ}$ & 22 & 0.011 & 1.5 & 0.00199 & 12.7 \\
\hline 18 & $60^{\circ}$ & 24 & 0.012 & 1.4 & 0.00166 & 12.6 \\
\hline 19 & $60^{\circ}$ & 26 & 0.013 & 1.3 & 0.00121 & 10.8 \\
\hline 20 & $60^{\circ}$ & 8 & 0.004 & 3.1 & 0.00321 & 6.5 \\
\hline 21 & $60^{\circ}$ & 10 & 0.005 & 2.4 & 0.00319 & 10.2 \\
\hline 22 & $60^{\circ}$ & 12 & 0.006 & 2.0 & 0.00261 & 12.0 \\
\hline 23 & $60^{\circ}$ & 14 & 0.007 & 1.7 & 0.00199 & 12.5 \\
\hline 24 & $60^{\circ}$ & 16 & 0.008 & 1.5 & 0.00172 & 14.0 \\
\hline 25 & $60^{\circ}$ & 20 & 0.01 & 1.2 & 0.00086 & 11.4 \\
\hline 26 & $60^{\circ}$ & 22 & 0.011 & 1.1 & 0.00089 & 13.8 \\
\hline 27 & $60^{\circ}$ & 24 & 0.012 & 1.0 & 0.00072 & 13.2 \\
\hline 28 & $60^{\circ}$ & 26 & 0.013 & 0.9 & 0.00049 & 10.7 \\
\hline 29 & $45^{\circ}$ & 6 & 0.0042 & 4.5 & 0.01169 & 7.2 \\
\hline 30 & $45^{\circ}$ & 7 & 0.005 & 3.8 & 0.00877 & 7.6 \\
\hline 31 & $45^{\circ}$ & 8 & 0.0056 & 3.4 & 0.00733 & 8.0 \\
\hline 32 & $45^{\circ}$ & 10 & 0.0071 & 2.7 & 0.00512 & 9.0 \\
\hline 33 & $45^{\circ}$ & 12 & 0.0085 & 2.2 & 0.00366 & 9.2 \\
\hline 34 & $45^{\circ}$ & 14 & 0.01 & 1.9 & 0.00280 & 9.7 \\
\hline 35 & $45^{\circ}$ & 16 & 0.0113 & 1.7 & 0.00240 & 10.6 \\
\hline 36 & $45^{\circ}$ & 18 & 0.0127 & 1.5 & 0.00225 & 12.5 \\
\hline 37 & $45^{\circ}$ & 19 & 0.0134 & 1.4 & 0.00177 & 10.9 \\
\hline 38 & $45^{\circ}$ & 6 & 0.0042 & 3.9 & 0.00787 & 7.7 \\
\hline 39 & $45^{\circ}$ & 7 & 0.005 & 3.3 & 0.00677 & 9.3 \\
\hline 40 & $45^{\circ}$ & 8 & 0.0056 & 2.9 & 0.00535 & 9.2 \\
\hline 41 & $45^{\circ}$ & 10 & 0.007 & 2.3 & 0.00339 & 9.1 \\
\hline 42 & $45^{\circ}$ & 12 & 0.0085 & 1.9 & 0.00226 & 8.9 \\
\hline 43 & $45^{\circ}$ & 14 & 0.01 & 1.6 & 0.00200 & 10.9 \\
\hline 44 & $45^{\circ}$ & 18 & 0.0127 & 1.3 & 0.00139 & 12.2 \\
\hline 45 & $45^{\circ}$ & 19 & 0.0134 & 1.2 & 0.00106 & 10.4 \\
\hline 46 & $45^{\circ}$ & 6 & 0.0042 & 2.9 & 0.00375 & 8.9 \\
\hline 47 & $45^{\circ}$ & 7 & 0.005 & 2.4 & 0.00355 & 11.9 \\
\hline 48 & $45^{\circ}$ & 8 & 0.0056 & 2.2 & 0.00261 & 11.0 \\
\hline 49 & $45^{\circ}$ & 10 & 0.007 & 1.7 & 0.00162 & 10.6 \\
\hline
\end{tabular}


Table 1 (continued)

\begin{tabular}{|c|c|c|c|c|c|c|}
\hline Sr. no & Jet angle $(\theta)$ & $Y(\mathrm{~mm})$ & $T_{\mathrm{j}}(\mathrm{m})$ & $V_{\mathrm{j}}(\mathrm{m} / \mathrm{s})$ & $K_{L} a\left(\mathrm{~s}^{-1}\right)$ & $\begin{array}{l}\text { SOTE } \\
(\mathrm{kg} / \\
\mathrm{kW} \mathrm{h})\end{array}$ \\
\hline 50 & $45^{\circ}$ & 12 & 0.0085 & 1.4 & 0.00114 & 11.0 \\
\hline 51 & $45^{\circ}$ & 14 & 0.01 & 1.2 & 0.00069 & 9.2 \\
\hline 52 & $45^{\circ}$ & 16 & 0.0113 & 1.1 & 0.00064 & 10.8 \\
\hline 53 & $45^{\circ}$ & 18 & 0.0127 & 1.0 & 0.00054 & 11.6 \\
\hline 54 & $30^{\circ}$ & 6 & 0.0052 & 3.7 & 0.01075 & 10.3 \\
\hline 55 & $30^{\circ}$ & 7 & 0.006 & 3.2 & 0.00795 & 10.2 \\
\hline 56 & $30^{\circ}$ & 8 & 0.007 & 2.7 & 0.00609 & 10.6 \\
\hline 57 & $30^{\circ}$ & 10 & 0.0087 & 2.2 & 0.00402 & 10.8 \\
\hline 58 & $30^{\circ}$ & 12 & 0.0104 & 1.8 & 0.00291 & 11.2 \\
\hline 59 & $30^{\circ}$ & 14 & 0.0121 & 1.6 & 0.00211 & 11.0 \\
\hline 60 & $30^{\circ}$ & 16 & 0.0138 & 1.4 & 0.00155 & 10.6 \\
\hline 61 & $30^{\circ}$ & 18 & 0.0156 & 1.2 & 0.00125 & 10.8 \\
\hline 62 & $30^{\circ}$ & 20 & 0.0173 & 1.1 & 0.00110 & 11.7 \\
\hline 63 & $30^{\circ}$ & 6 & 0.0052 & 3.2 & 0.00664 & 9.9 \\
\hline 64 & $30^{\circ}$ & 7 & 0.0061 & 2.7 & 0.00494 & 10.2 \\
\hline 65 & $30^{\circ}$ & 8 & 0.007 & 2.3 & 0.00379 & 10.4 \\
\hline 66 & $30^{\circ}$ & 10 & 0.0087 & 1.9 & 0.00259 & 10.9 \\
\hline 67 & $30^{\circ}$ & 12 & 0.0104 & 1.6 & 0.00180 & 10.9 \\
\hline 68 & $30^{\circ}$ & 14 & 0.0121 & 1.4 & 0.00157 & 12.8 \\
\hline 69 & $30^{\circ}$ & 16 & 0.0139 & 1.2 & 0.00107 & 11.4 \\
\hline 70 & $30^{\circ}$ & 18 & 0.0156 & 1.1 & 0.00077 & 10.4 \\
\hline 71 & $30^{\circ}$ & 20 & 0.0173 & 1.0 & 0.00067 & 11.1 \\
\hline 72 & $30^{\circ}$ & 6 & 0.0052 & 2.3 & 0.00294 & 10.8 \\
\hline 73 & $30^{\circ}$ & 7 & 0.0061 & 2.0 & 0.00232 & 11.8 \\
\hline 74 & $30^{\circ}$ & 8 & 0.007 & 1.7 & 0.00179 & 12.0 \\
\hline 75 & $30^{\circ}$ & 10 & 0.0087 & 1.4 & 0.00120 & 12.4 \\
\hline 76 & $30^{\circ}$ & 12 & 0.0104 & 1.2 & 0.00087 & 12.9 \\
\hline 77 & $30^{\circ}$ & 14 & 0.0121 & 1.0 & 0.00071 & 14.1 \\
\hline 78 & $30^{\circ}$ & 17 & 0.0145 & 0.8 & 0.00059 & 16.8 \\
\hline 79 & $30^{\circ}$ & 18 & 0.0156 & 0.8 & 0.00041 & 13.7 \\
\hline 80 & $30^{\circ}$ & 20 & 0.0173 & 0.7 & 0.00034 & 13.7 \\
\hline
\end{tabular}

Table 2 Details of the training and testing data sets

\begin{tabular}{|c|c|c|c|c|c|c|c|c|}
\hline \multirow[t]{2}{*}{ Parameter } & \multicolumn{4}{|c|}{ Training data set } & \multicolumn{4}{|c|}{ Testing data set } \\
\hline & Min. & Max. & Mean & SD & Min. & Max. & Mean & SD \\
\hline$T_{j}(\mathrm{~m})$ & 0.004 & 0.0173 & 0.009 & 0.004 & 0.004 & 0.0173 & 0.009 & 0.004 \\
\hline$V_{j}(\mathrm{~m} / \mathrm{s})$ & 0.705 & 4.775 & 1.98 & 0.836 & 0.939 & 4.546 & 2.218 & 1.1 \\
\hline $\sin \theta$ & 0.5 & 0.866 & 0.694 & 0.154 & 0.5 & 0.866 & 0.691 & 0.153 \\
\hline$K_{L} a\left(\mathrm{~s}^{-1}\right)$ & 0.00034 & 0.0136 & 0.00307 & 0.00257 & 0.00049 & 0.01169 & 0.00405 & 0.0035 \\
\hline
\end{tabular}

The value of learning rate (the rate by which the weights are adjusted), momentum (momentum applied to the weights during updating) and the number of iterations was selected as $0.5,0.1$ and 2500 , respectively, in the present study, and the sensitivity of ANN was tested by varying the hidden layer neurons from 1 to 18 on both training and testing data sets. The performance evaluation of the models is done on the basis of coefficient of determination $\left(R^{2}\right)$, root mean square error (RMSE) and mean absolute error (MAE) values. The ANN modeling results with varying hidden layer neurons, represented in Table 3, revealed that MLP with 16 hidden layer neurons (3-16-1) is best of all other tested ANN models in prediction due to higher value of $R^{2}$ and minimum value of RMSE and MAE (Table 3, Fig. 8) in both training and 
Table $3 R^{2}$, RMSE and MAE statistics for each ANN model during training and testing phases

\begin{tabular}{|c|c|c|c|c|c|c|}
\hline \multirow[t]{2}{*}{ MLP structure } & \multicolumn{3}{|c|}{ Training } & \multicolumn{3}{|c|}{ Testing } \\
\hline & $\overline{R^{2}}$ & RMSE & MAE & $\overline{R^{2}}$ & RMSE & MAE \\
\hline $3-1-1$ & 0.94 & 0.000645 & 0.000396 & 0.985 & 0.000454 & 0.000342 \\
\hline $3-2-1$ & 0.964 & 0.00053 & 0.000386 & 0.98 & 0.000536 & 0.00044 \\
\hline $3-3-1$ & 0.982 & 0.000435 & 0.000331 & 0.931 & 0.00092 & 0.000552 \\
\hline $3-4-1$ & 0.983 & 0.000526 & 0.00045 & 0.938 & 0.000904 & 0.00062 \\
\hline $3-5-1$ & 0.984 & 0.000413 & 0.000307 & 0.987 & 0.000417 & 0.000293 \\
\hline $3-6-1$ & 0.984 & 0.00037 & 0.000254 & 0.99 & 0.000361 & 0.000253 \\
\hline $3-7-1$ & 0.983 & 0.000515 & 0.000432 & 0.983 & 0.000551 & 0.000459 \\
\hline $3-8-1$ & 0.983 & 0.000516 & 0.000431 & 0.985 & 0.000538 & 0.000442 \\
\hline $3-9-1$ & 0.984 & 0.000499 & 0.00042 & 0.985 & 0.00054 & 0.000437 \\
\hline $3-10-1$ & 0.985 & 0.000452 & 0.000373 & 0.986 & 0.000485 & 0.000393 \\
\hline $3-11-1$ & 0.985 & 0.000317 & 0.000219 & 0.986 & 0.000414 & 0.000323 \\
\hline $3-12-1$ & 0.987 & 0.000299 & 0.000206 & 0.988 & 0.000381 & 0.000288 \\
\hline $3-13-1$ & 0.987 & 0.000299 & 0.000206 & 0.987 & 0.000394 & 0.0003 \\
\hline $3-14-1$ & 0.988 & 0.00028 & 0.000191 & 0.989 & 0.000369 & 0.000278 \\
\hline $3-15-1$ & 0.989 & 0.00028 & 0.000191 & 0.989 & 0.000361 & 0.000272 \\
\hline $3-16-1$ & 0.988 & 0.000282 & 0.000194 & 0.99 & 0.000351 & 0.00027 \\
\hline $3-17-1$ & 0.988 & 0.000284 & 0.000196 & 0.99 & 0.000354 & 0.000272 \\
\hline $3-18-1$ & 0.988 & 0.00028 & 0.000193 & 0.988 & 0.000362 & 0.000275 \\
\hline
\end{tabular}

Fig. 8 Variation of coefficient of determination $\left(R^{2}\right)$ and RMSE with hidden layer neurons during training and testing phases

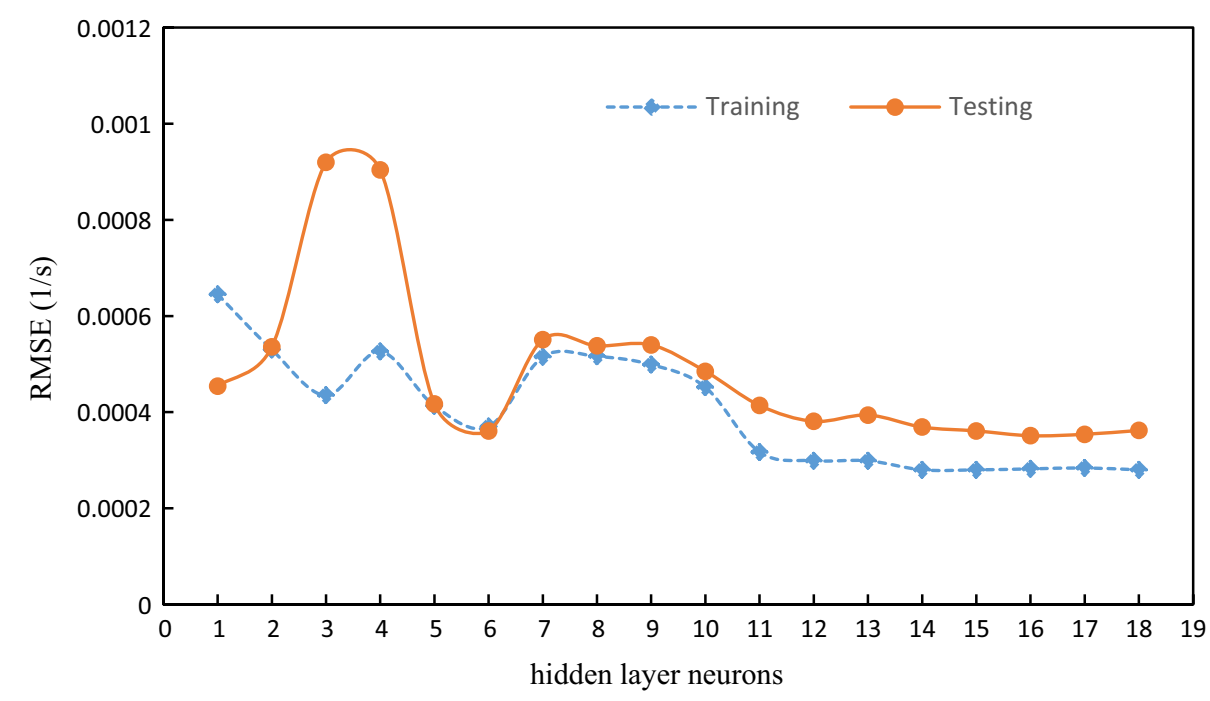

testing phases; hence, this optimal model is selected for performance comparison with the other regression models.

\section{Multiple linear regression}

Multiple linear regression (MLR) is a method used to model the linear relationship between a dependent variable and one or more independent variables. MLR is based on least squares: The model is fit such that the sum of squares of differences in observed and predicted values is minimized (Onen 2014). Multiple linear functions of interest are as follows:
$Y=a+b_{1} X_{1}+b_{2} X_{2}+b_{3} X_{3}$

where $Y$ is the value of the dependent variable; $a$ is the constant; $b_{1}$ is the slope for $X_{1} ; X_{1}$ is the first independent variable that is explaining the variance in $Y ; b_{2}$ is the slope for $X_{2} ; X_{2}$ is the second independent variable that is explaining the variance in $Y ; b_{3}$ is the slope for $X_{3} ; X_{3}$ is the third independent variable that is explaining the variance in $Y$. The following equation is derived after applying multiple linear regression to the training data set:

$K_{L} a=-0.00732+0.29334 T_{\mathrm{j}}+0.00383 V_{\mathrm{j}}-0.0001 \sin \theta$ 


\section{Multiple nonlinear regression}

Deswal and Verma (2007b) investigated the aeration performance of conical plunging jet aerator (jet angle $60^{\circ}$ ) for a thickness range of 1.9-3.77 $\mathrm{mm}$ and reported the following

$K_{L} a \propto V_{\mathrm{j}}^{1.98} T_{\mathrm{j}}^{0.74}$

In a similar way, a nonlinear relationship of $K_{L} a$ is purposed based on jet velocity, jet thickness and jet angle of hollow jet aerators (Kumar et al. 2018).

Functional relationship of interest is as follows:

$Y=a X_{1}^{b_{1}} X_{1}^{b_{1}} \cdots X_{n}^{b_{n}}$

Nonlinear relationship between the dependent variables and the independent variables based on multivariate power function was considered, and the following equation is derived from the training data set:

$K_{L} a=0.054 V_{\mathrm{j}}^{2.716} T_{\mathrm{j}}^{1.023}(\sin \theta)^{-0.198}$

\section{Modeling results}

ANN modeling results are compared with the applied regression techniques to the current data of oxygen transfer considering jet thickness $\left(T_{\mathrm{j}}\right)$, jet velocity $\left(V_{\mathrm{j}}\right)$ and jet angle $(\sin \theta)$ as inputs and volumetric oxygen transfer coefficient $\left(K_{L} a\right)$ as output. Models are generated on the training data set and validated on the testing data set for all the three modeling techniques. Statistical parameters ( $R^{2}$ and RMSE and MAE) were used to evaluate the performance of modeling techniques. Figure 9 shows scatter plots of training data set denoted by error line diagrams $( \pm 15 \%)$ for optimal ANN model (3-16-1), multiple linear regression and multiple nonlinear regression, and the results are represented in the same way for the testing data set in Fig. 10. It is clear from both figures (Figs. 9, $10)$ that the modeling results are well within the range of $\pm 15 \%$ error lines, which signifies good predictability of all the utilized modeling techniques in forecasting volumetric oxygen transfer coefficient. However, linear regression (Eq. 9) approach predicted output deviates at couple of points from the $\pm 15 \%$ error line with training data set with lower value of $R^{2}(0.936)$ and higher values of RMSE (0.000644) and MAE (0.00042) suggesting inferior performance in building regression model, but the testing results are encouraging $\left(R^{2}=0.983\right.$, RMSE $=0.000518$ and $\mathrm{MAE}=0.000401)$ and lesser deviation was observed in testing plot as the predicted points are in close proximity to the agreement line. A slight variation in $R^{2}$ values was observed in both regression modeling approaches (linear and nonlinear) with the testing data set, but lower values of MAE (0.000323) and RMSE (0.000484) obtained from nonlinear regression (Eq. 12) suggest better prediction of multiple nonlinear regression in comparison with multiple linear regression approach. The modeling results of both ANN and nonlinear regression are positive on both training and testing data sets in prediction. Of all the tested models, the prediction performance of ANN is best in both training $\left(R^{2}=0.988, \mathrm{RMSE}=0.000282, \mathrm{MAE}=0.000194\right)$ and testing data $\left(R^{2}=0.99\right.$, RMSE $=0.000351$, $\mathrm{MAE}=0.00027)$ followed by nonlinear and linear regression models, respectively (Table 4).

Figure 11 suggests that used ANN model achieves close approximations of the experimental observations in both training and testing phases, suggesting usefulness of this modeling technique in predicting $K_{L} a$ values of hollow jet aeration devices. The predicted points of linear regression model do not follow the same pattern and found differing
Fig. 9 Experimental versus predicted values of $K_{L} a$ by nonlinear regression, linear regression and ANN with training data

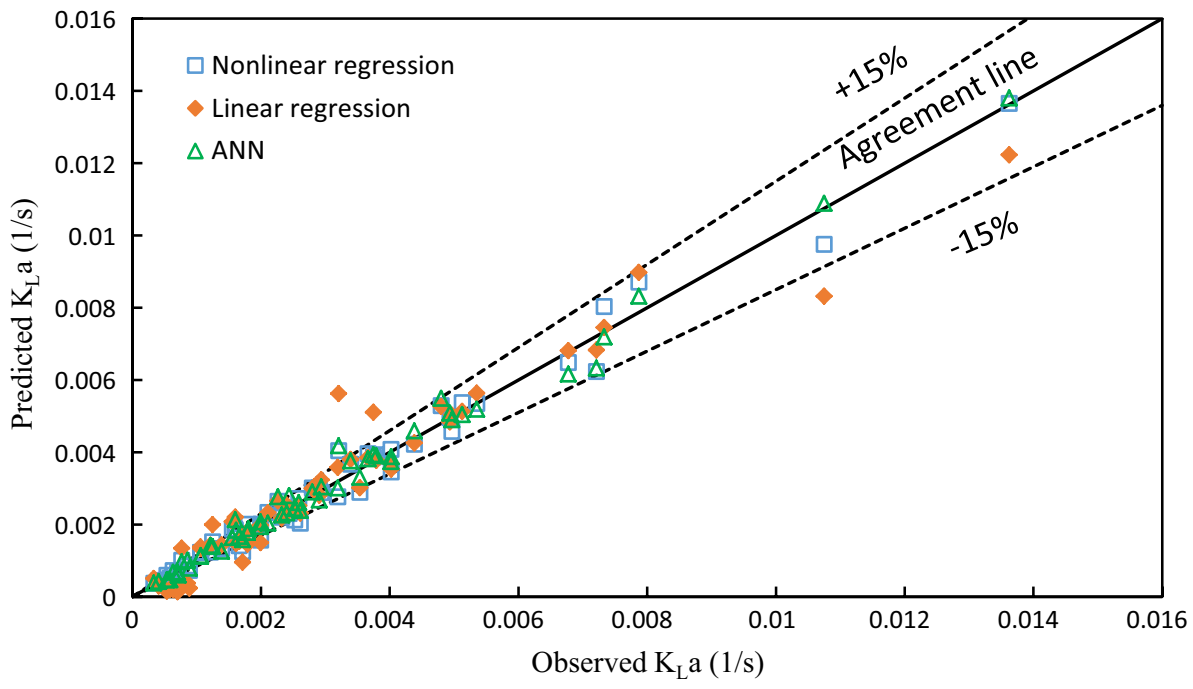


Fig. 10 Experimental versus predicted values of $K_{L} a$ by nonlinear regression, linear regression and ANN with testing data

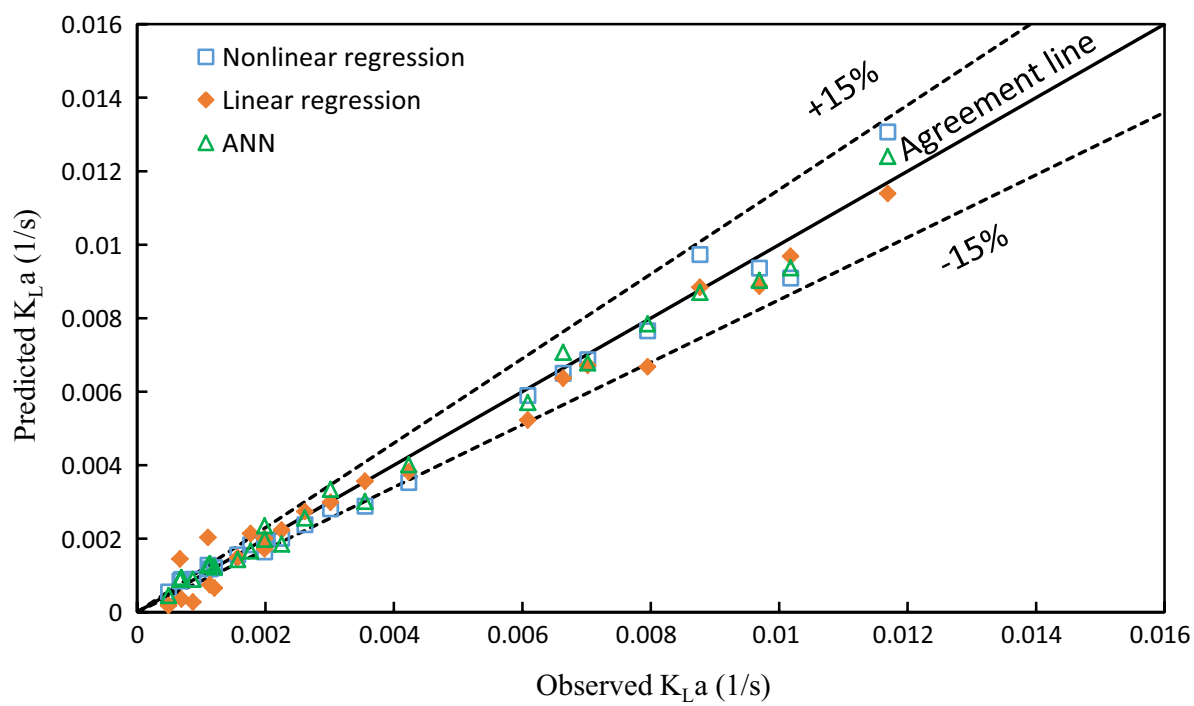

Table 4 Detail of performance evaluation parameters using regression and ANN models of the data set

\begin{tabular}{llllllll}
\hline Modeling & \multicolumn{3}{l}{ Training } & & \multicolumn{2}{l}{ Testing } \\
\cline { 2 - 3 } & $R^{2}$ & $\operatorname{RMSE}\left(\mathrm{s}^{-1}\right)$ & $\operatorname{MAE}\left(\mathrm{s}^{-1}\right)$ & & $R^{2}$ & $\operatorname{RMSE}\left(\mathrm{s}^{-1}\right)$ & $\operatorname{MAE}\left(\mathrm{s}^{-1}\right)$ \\
\hline Linear regression & 0.936 & 0.000644 & 0.00042 & & 0.983 & 0.000518 & 0.000401 \\
Nonlinear regression & 0.98 & 0.000359 & 0.000256 & & 0.981 & 0.000484 & 0.000323 \\
ANN & 0.988 & 0.000282 & 0.000194 & & 0.99 & 0.000351 & 0.00027
\end{tabular}

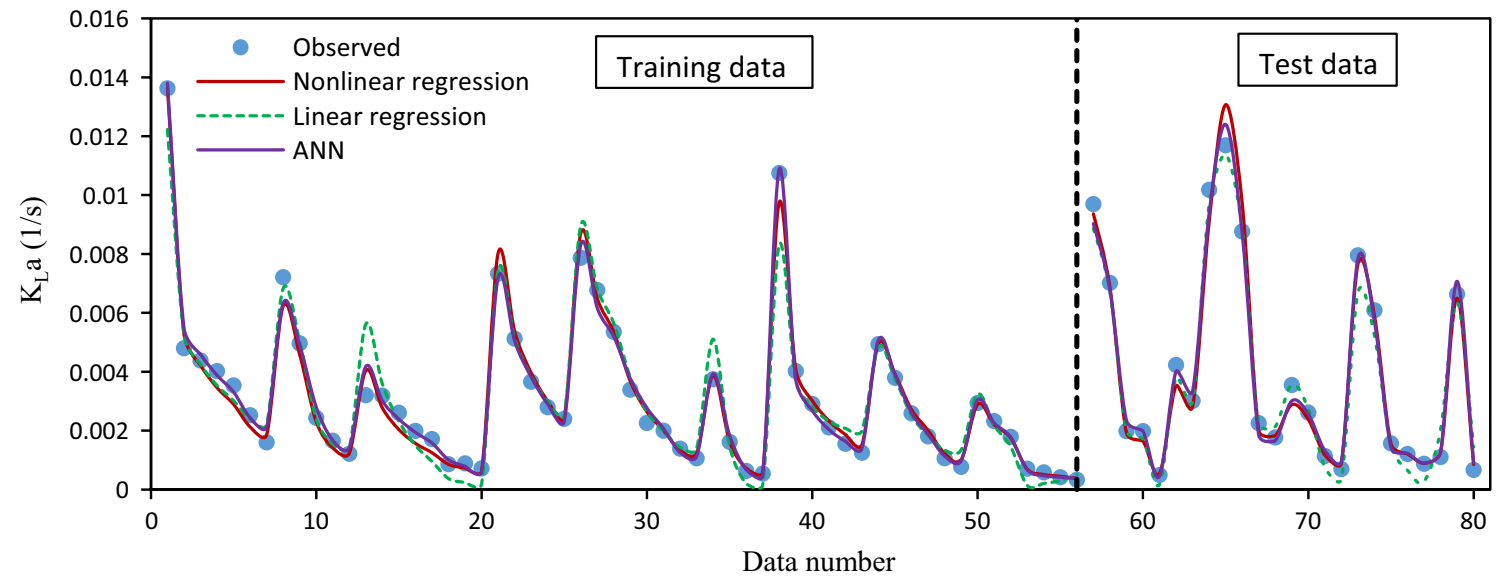

Fig. 11 Variation in predicted values of $K_{L} a$ using different modeling approaches in comparison with experimental values of $K_{L} a$ during training and testing phases

more than nonlinear regression model for some of the data points.

The results of the present study are compared with the existing studies on plunging jet aeration devices (Fig. 12) and represented with the testing data set results obtained from Eq. (12) (nonlinear regression). The plot provides information about experimental versus predicted values of $K_{L} a$ with proposed empirical relationships for various plunging jet aeration systems and represented by an agreement line. It is evident from the figure that predicted points of Eq. (12) lie close to the agreement line. The relationship proposed by Tojo and Miyanami (1982) for cylindrical nozzle jets is underperformed in predicting the $K_{L} a$ values of hollow jets and has the highest value of MAE (0.002394) (Table 5). The predicted points of single radial jet (Deswal and Verma 2007a) lie close to the observed data (particularly at higher $K_{L} a$ values) in comparison with all the other aeration devices and have least MAE value of 
0.00084 (Table 5). On the other hand, conical hollow jet predicted points are in close proximity to the agreement line for smaller $K_{L} a$ values and scatter more at higher $K_{L} a$ values, possibly due to much wider range of jet thicknesses studied in the present study of hollow jet aerators relative to study conducted by Deswal and Verma (2007b), and the plotting results support the statement made by the author that thicker jet results in higher $K_{L} a$ values. The predicted points of $K_{L} a$ are observed highest with inclined radial jet having a much higher values of RMSE (0.00209) and MAE (0.001923) for the current testing data set and lie distant from the agreement line which is probably because deeper penetration with the radial jets improves the bubble retention time and so is the oxygen transfer.

\section{Comparison with plunging jet aeration devices}

Table 6 delivers information about the oxygen transfer performance of different plunging jet aeration systems, and it is noticeable from Table 6 that plunging hollow jets are comparable to most of the aeration equipment.
Fig. 12 Experimental versus predicted values of $K_{L} a$ by nonlinear regression (Eq. 12) and previous studies on jet aerators with the testing data set

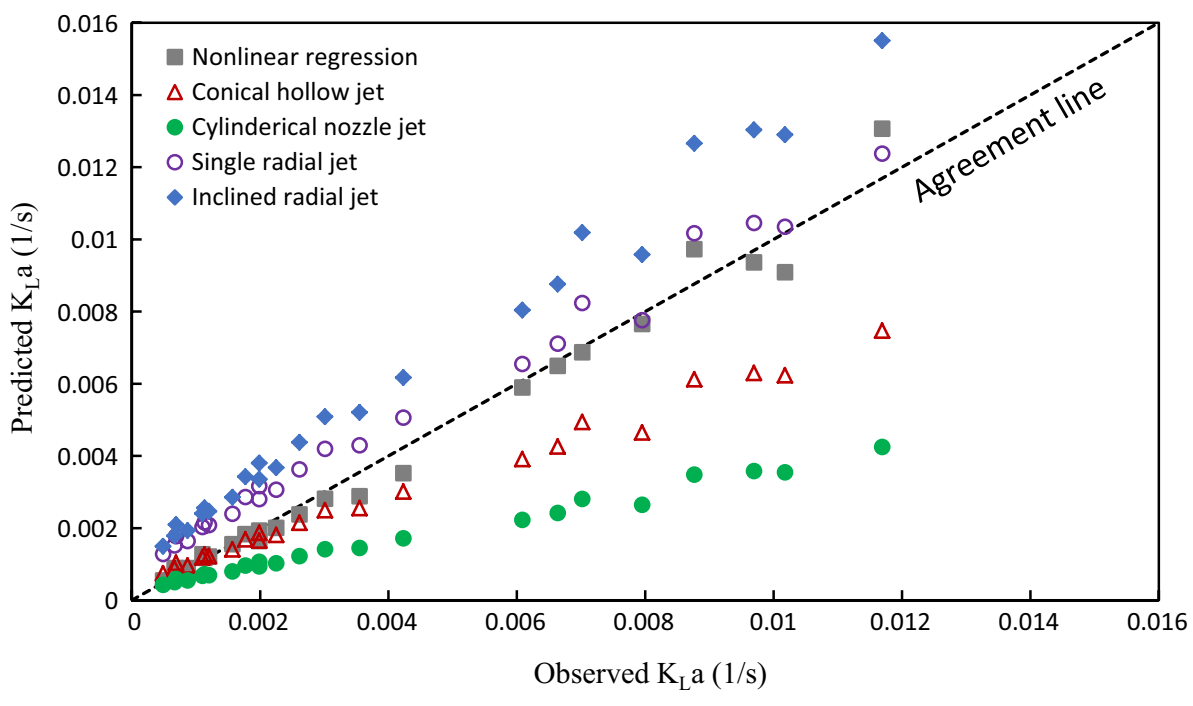

Table $5 R^{2}$ RMSE $\left(\mathrm{s}^{-1}\right)$ and MAE $\left(\mathrm{s}^{-1}\right)$ of proposed correlations with testing data set

\begin{tabular}{llllll}
\hline Nozzle type & Correlation & $R^{2}$ & RMSE $\left(\mathrm{s}^{-1}\right)$ & MAE $\left(\mathrm{s}^{-1}\right)$ & Source \\
\hline Conical hollow jet & $K_{L} a=0.051(P / V)^{0.65}$ & 0.991 & 0.00184 & 0.001234 & Deswal and Verma (2007b) \\
Cylindrical nozzle jet & $K_{L} a=0.029(P / V)^{0.65}$ & 0.991 & 0.00332 & 0.002394 & Tojo and Miyanami (1982) \\
Single radial jet & $K_{L} a=0.082(P / V)^{0.64}$ & 0.991 & 0.00089 & 0.00084 & Deswal and Verma (2007a) \\
Single inclined radial jet & $K_{L} a=0.109(P / V)^{0.66}$ & 0.991 & 0.00209 & 0.001923 & Deswal (2008) \\
\hline
\end{tabular}

Table 6 Oxygen transfer efficiency comparison with different aeration systems

\begin{tabular}{lll}
\hline Equipment & SOTE $(\mathrm{kg} / \mathrm{kW} \mathrm{h})$ & Source \\
\hline Plunging jet & $0.92-3.9$ & Tojo and Miyanami (1982) \\
Plunging venturi device & $2.2-8.8$ & Emiroglu and Baylar (2003) \\
Single plunging jet $\left(\theta=90^{\circ}\right)$ & $5.2-19.3$ & Deswal and Verma (2007a) \\
Multiple plunging jets $\left(\theta=90^{\circ}\right)$ & $6.0-21.3$ & Deswal and Verma (2007a) \\
Conical plunging jet $\left(\theta=60^{\circ}\right)$ & $2.56-10.73$ & Deswal and Verma (2007b) \\
Multiple plunging jets $\left(\theta=60^{\circ}\right)$ & $8.2-24.5$ & Deswal (2008) \\
Multiple plunging tandem jets & $1.52-17.4$ & Chipongo and Khiadani (2016) \\
$\left(\theta=90^{\circ}\right)$ into moving water & & Present work \\
Plunging hollow jets & $6.53-16.8$ & \\
\hline
\end{tabular}




\section{Conclusions}

The overall oxygen transfer performance of hollow jet angle of $30^{\circ}$ is found better than the jet angles of $45^{\circ}$ and $60^{\circ}$. However, the performance of jet angles of $30^{\circ}$ and $60^{\circ}$ is comparable at low-power jets. The modeling results suggest that ANN technique is superior and outperformed both multiple linear regression and multiple nonlinear regression techniques in predicting volumetric oxygen transfer coefficient of hollow jet aerators. The modeled volumetric oxygen transfer coefficient values are in good agreement with the experimental results. Correlation derived from nonlinear regression is found to work well as compared to linear regression; hence, the relation simply can be helpful in deciding finest configurations of hollow jet aerators; however, the utility is limited to the current experimental range.

The present study results on hollow jets are comparable to the existing published work on oxygen transfer efficiency of different plunging jet aerators and show a great potential in the application of waste water treatment and mixing applications due to its flexibility in adjustment of jet area, and hence quite useful in handling waste water of different characteristics. These aerators can be effectively operated with aeration tanks having larger water surface area due to its jet spreading nature.

Open Access This article is distributed under the terms of the Creative Commons Attribution 4.0 International License (http://creativeco mmons.org/licenses/by/4.0/), which permits unrestricted use, distribution, and reproduction in any medium, provided you give appropriate credit to the original author(s) and the source, provide a link to the Creative Commons license, and indicate if changes were made.

\section{References}

Ahmed A (1974) Aeration by plunging liquid jet. Doctoral thesis, Loughborough University of Technology

APHA, AWWA, WEF (2005) Standard methods for the examination of water and wastewater. APHA, Washington, pp. 4.38-4.140

Ashley K, Fattah K, Mavinic D, Kosari S (2013) Analysis of design factors influencing the oxygen transfer of a pilot-scale Speece Cone hypolimnetic aerator. J Environ Eng 140(3):04013011

Bagatur T, Baylar A, Sekerdag N (2002) The effect of nozzle type on air entrainment by plunging water jets. Water Qual Res J Can 37(3):599-612

Bin AK (1993) Gas entrainment by plunging liquid jets. Chem Eng Sci 48(21):3585-3630

Bishop CM (1995) Neural networks for pattern recognition. Oxford University Press, Oxford

Chipongo K, Khiadani M (2016) Oxygen transfer by multiple vertical plunging jets in tandem. J Environ Eng 143(1):04016072. https:// doi.org/10.1061/(asce)ee.1943-7870.0001145

Conway RA, Kumke GW (1966) Field techniques for evaluating aerators. J Sanit Eng Divi 92(2):21-42

Daniil EI, Gulliver JS (1988) Temperature dependence of liquid film coefficient for gas transfer. J Environ Eng 114(5):1224-1229

Deswal S (2008) Oxygen transfer by multiple inclined plunging water jets. Int J Civ Environ Struct Constr Archit Eng 2(3):57-63
Deswal S (2011) Modeling oxygen-transfer by multiple plunging jets using support vector machines and gaussian process regression techniques. Int J Civ Environ Struct Constr Archit Eng 5(1):1-6

Deswal S, Pal M (2015) Comparison of polynomial and radial basis kernel functions based SVR and MLR in modeling mass transfer by vertical and inclined multiple plunging jets. Int J Civ Environ Struct Constr Archit Eng 9(9):1236-1240

Deswal S, Verma DVS (2007a) Air-water oxygen transfer with multiple plunging jets. Water Qual Res J Can 42(4):295-302

Deswal S, Verma DVS (2007b) Performance evaluation and modeling of a conical plunging jet aerator. Int J Mech Aerosp Ind Mechatron Manuf Eng 1(11):616-620

Emiroglu ME, Baylar A (2003) Study of the influence of air holes along length of convergent-divergent passage of a venturi device on aeration. J Hydraul Res 41(5):513-520

Fischer MM (1998) Computational neural networks: a new paradigm for spatial analysis. Environ Plan A 30(10):1873-1891

Jahromi ME, Khiadani M (2017) Experimental study on oxygen transfer capacity of water jets discharging into turbulent cross-flow. J Environ Eng 143(6):04017007. https://doi.org/10.1061/(asce)ee.19437870.0001194

Kumar M, Tiwari NK, Ranjan S (2018) Prediction of oxygen mass transfer of plunging hollow jets using regression models. ISH J Hydraul Eng. https://doi.org/10.1080/09715010.2018.1435311

Ohkawa A, Kusabiraki D, Shiokawa Y, Sakai N, Fujii M (1986) Flow and oxygen transfer in a plunging water jet system using inclined short nozzles and performance characteristics of its system in aerobic treatment of wastewater. Biotechnol Bioeng 28(12):1845-1856

Onen F (2014) Prediction of penetration depth in a plunging water jet using soft computing approaches. Neural Comput Appl 25(1):217-227

Pillai NN, Wheeler WC, Prince RP (1971) Design and operation of an extended aeration plant. J (Water Pollut Control Fed) 43(7):1484-1498

Quej VH, Almorox J, Arnaldo JA, Saito L (2017) ANFIS, SVM and ANN soft-computing techniques to estimate daily global solar radiation in a warm sub-humid environment. J Atmos Solar Terr Phys 155:62-70

Sene KJ (1988) Air entrainment by plunging jets. Chem Eng Sci 43(10):2615-2623

Sihag P, Tiwari NK, Ranjan S (2017) Modelling of infiltration of sandy soil using gaussian process regression. Model Earth Syst Environ 3(3):1091-1100

Sihag P, Jain P, Kumar M (2018a) Modelling of impact of water quality on recharging rate of storm water filter system using various kernel function based regression. Model Earth Syst Environ 4(1):61-68

Sihag P, Singh B, Sepah Vand A, Mehdipour V (2018b) Modeling the infiltration process with soft computing techniques. ISH J Hydraul Eng. https://doi.org/10.1080/09715010.2018.1464408

Sihag P, Tiwari NK, Ranjan S (2018c) Support vector regression-based modeling of cumulative infiltration of sandy soil. ISH J Hydraul Eng. https://doi.org/10.1080/09715010.2018.1439776

Singh S, Deswal S, Pal M (2011) Performance analysis of plunging jets having different geometries. Int J Environ Sci 1(6):1154-1167

Singh B, Sihag P, Singh K (2017) Modelling of impact of water quality on infiltration rate of soil by random forest regression. Model Earth Syst Environ 3(3):999-1004

Tojo K, Miyanami K (1982) Oxygen transfer in jet mixers. Chem Eng J 24(1):89-97

Tojo K, Naruko N, Miyanami K (1982) Oxygen transfer and liquid mixing characteristics of plunging Jet reactors. Chem Eng J 25(1):107-109

Van de Donk JAC (1981) Water aeration with plunging jets. Doctoral thesis. Technische Hogeschool Delft

Van de Sande E (1974) Air entrainment by plunging water jets. Doctoral thesis. Technische Hogeschool Delft

Van de Sande E, Smith JM (1975) Mass transfer from plunging water jets. Chem Eng J 10(3):225-233 
Publisher's Note Springer Nature remains neutral with regard to jurisdictional claims in published maps and institutional affiliations. 